\title{
Dynamics and control of ocean wave energy converters
}

\author{
Jingjin Xie • Lei Zuo
}

Received: 10 July 2013 / Revised: 28 July 2013 / Accepted: 2 August 2013 / Published online: 16 August 2013

(C) Springer-Verlag Berlin Heidelberg 2013

\begin{abstract}
Ocean wave technology is one of the most exciting areas due to vast but untapped energy potential worldwide. Technologies on ocean wave harvesting energy have been explored for centuries and are still undergoing with challenges. This paper provides a comprehensive literature review on the progress of classical and modern control strategies, including latching control, declutch control, reactive control, model predictive control, state space control, etc. For three major types of ocean wave energy converters (OWECs), i.e. oscillating-body wave energy converter (including point absorber, attenuator and terminator), oscillating water column and overtopping device. It also introduces the nature of ocean waves, mathematical models of ocean wave energy and the hydrodynamics of the representative OWECs.
\end{abstract}

Keywords Ocean wave energy - Wave energy converter . OWEC $\cdot$ Hydrodynamics $\cdot$ Control

\section{Introduction}

With the shortage of global energy, it's highly necessary to exploit alternative renewable energy sources beyond fossil oil, nuclear, solar and wind energy. Ocean wave energy is gradually becoming an important alternative energy due to its vast but untapped potential. The world's ocean wave energy has the potential of approximately 8,000-80,000 TW every year [1]. In the U.S. alone, the tremendous potential has been evaluated in the research report finished by Electric Power Research Institute (EPRI) which shows the total available

J. Xie · L. Zuo (凶)

Mechanical Engineering Department, State University of New York at Stony Brook, Stony Brook, NY 11794, USA

e-mail: lei.zuo@stonybrook.edu wave energy resource along the U.S. continental shelf edge is estimated to be 2,640 TWh/year, which is $64 \%$ of the electricity generated in $2010(4,125 \mathrm{TWh})$. Among them, the total extractable wave energy resource is $1,170 \mathrm{TWh} /$ year, which is composed of $250 \mathrm{TWh} /$ year for the West Coast, $160 \mathrm{TWh} /$ year for the East Coast, $60 \mathrm{TWh} /$ year for the Gulf of Mexico, $620 \mathrm{TWh} /$ year for the Alaska, $80 \mathrm{TWh} /$ year for Hawaii, and $20 \mathrm{TWh} /$ year for the Puerto Rico [2]. Theoretically, if all the extractable energy can be harvested, it can feed $1 / 4$ of the U.S. national need of the electricity.

In other countries and regions in the world, ocean wave energy also demonstrates its great potential to feed the energy demands. In China, it has approximately $249.7 \mathrm{TWh} /$ year near-shore ocean wave energy resource extractable and about ten provinces have the ocean wave energy potential higher than $850 \mathrm{GWh} /$ year $[3,4]$. In Europe, the total ocean wave energy is assessed to be $16 \%$ of the total world ocean wave energy resource [5]. Many European countries, such as Spain, Portugal, UK, etc., developed many leading ocean wave energy technologies in the past century.

Ocean wave energy is clean and renewable compared to conventional energy resources such as coal, oil and gas. Wave power density averages up to $50 \mathrm{~kW}$ per meter of wave front near the coast, and it can be as high as $100 \mathrm{KW} / \mathrm{m}$ off shore $[2,6]$. As a consequence, project footprints are smaller than the one with less energy-dense sources such as wind and solar. The low profile of wave energy converters further reduces their visual impact.

Great potential and advantages of ocean wave energy encourage people to strive for various wave harvesting technologies, to convert the kinetic energy from surface waves into electricity or make it available directly for other purposes, like desalinization. Recorded interest in energy harvesting from ocean waves dates back to a patent in 1799 [7], since then more than one thousand patents had been filed by 
1980 [8]. However, very few of them had been developed to practical applications. Modern research on wave energy harvesting technologies started following the oil crisis in early 1970s. The U.K. and Norwegian Governments initiated important R\&D programs in wave energy in 1975, and the European Commission started significant R\&D efforts in the early 1990s. Scotland has a goal of producing $2 \mathrm{GW}$ from ocean waves by 2020 [6]. The U.K. has established a goal to produce $20 \%$ of its electricity from ocean renewable technologies by 2020 , and Ireland has established a goal of 500 MW by $2020[9,10]$.

According to their working principle and working conditions, different types of ocean wave energy converter (OWEC) can be classified into three categories [11]: (1) Oscillating-body wave energy converter, including point absorber, attenuator and terminator, which use a float, buoy, or pitching device to tap the oscillating force of the waves to generate electricity; (2) oscillating water column (OWC), in which water enters into a chamber and forces the trapped air though an opening connected to a turbine; and (3) overtopping device, with a reservoir above mean water level from which wave water flows through one or more conventional low-head hydraulic turbines. The energy converting unit, known as power take-off (PTO) is the key part in the OWEC to convert the wave kinetic energy into electricity. PTOs have various forms such as hydraulic [12,13], linear generator [14], air-driven turbine [15,16], hose pump [17], etc. A recent innovation of mechanical motion rectifier (MMR) which can convert the bidirectional oscillatory motion to unidirectional rotation [18] may be extended to ocean wave PTO to enhance the efficiency, reliability and compactness of the OWECs.

The primary objective of this paper is to provide a comprehensive technical review on the development of ocean wave energy harvesting technologies, especially dynamics and control strategies since the 1900s to 2013. Dynamics and control are crucial to ocean wave energy conversion since the random nature and short-time unpredictability of the ocean wave may lead to great challenge to efficient energy conversion. The aim of controlling OWEC is to achieve an optimum wave-OWEC interaction and to maximize the energy absorption. It is recognized that the thrust for widely utilizing the ocean wave energy not only depends on the reliable and efficient OWEC design but also, at the same importance, relies on the control strategy scheming. This review also offers an overlook to understand the physics behind the phenomenal scenes of ocean waves by explaining some key concepts related to ocean and coastal engineering.

This paper is organized as following: in Sect. 2 we start with the major features of the aforementioned three categorized OWECs and some typical applications in each. Then fundamental wave formations, the factors determining the wave energy and some physical concepts used in ocean wave energy conversion technologies are introduced followed by

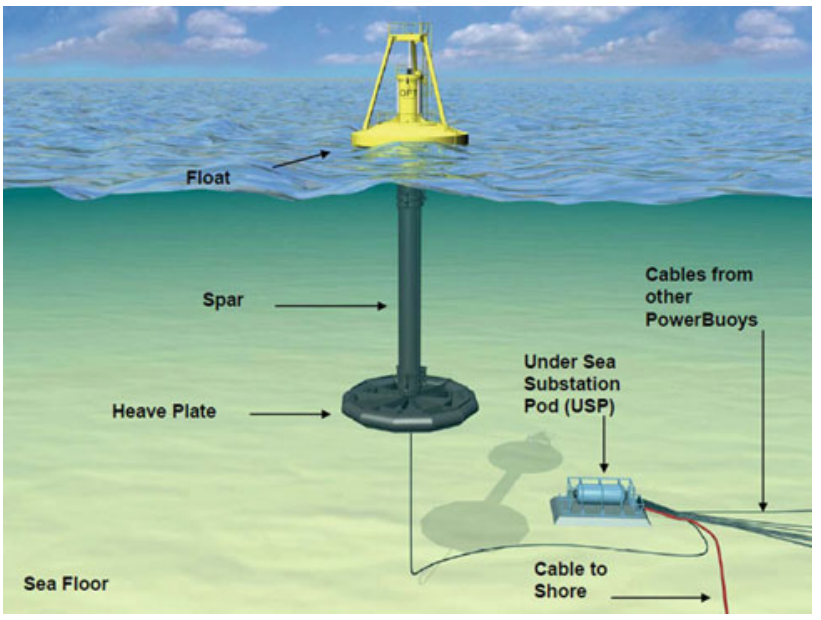

Fig. 1 Working principle of point absorber [11]

the hydrodynamics of each type of OWECs in Sect. 3. And in Sects. 4, 5 and 6 we will review the control strategies for point absorbers, attenuators and OWCs, respectively. In the end of the paper, we will summarize the main contribution of this paper and raise some of our comments and suggestions on the development of ocean wave energy technologies.

\section{Ocean wave energy converters}

This section will briefly review the major type of OWECs: float type, OWC, and overtopping devices.

\subsection{Oscillating bodies}

By utilizing the wave induced oscillation of float bodies, the devices can extract energy from ocean wave. Generally, this category can be further divided into three types: point absorber, attenuator and terminator. In the following, we will mainly review the point absorber and attenuator since attenuator shares many similarities with terminator such as the rotational motion, the actuation mechanisms and PTOs (mainly hydraulic systems).

Point absorber is a typical style of float oscillating body, which usually utilizes a submerged or floating body to trap the oscillating force of the wave. It mostly uses vertical translational motion for its actuation mechanisms. The advantage of point absorber is that it can harvest energy from waves in all directions at one point in the ocean. It's usually placed at or near the ocean surface away from the shoreline and may occupy a variety of ocean depths ranging from shallow to very deep water depending on the OWEC design and the mooring system. Typical point absorbers are: PowerBuoy [19] (Fig. 1), AquaBuoy [20], WaveBob [21], SEAREV [22], Archimedes Wave Swing [23], etc. 


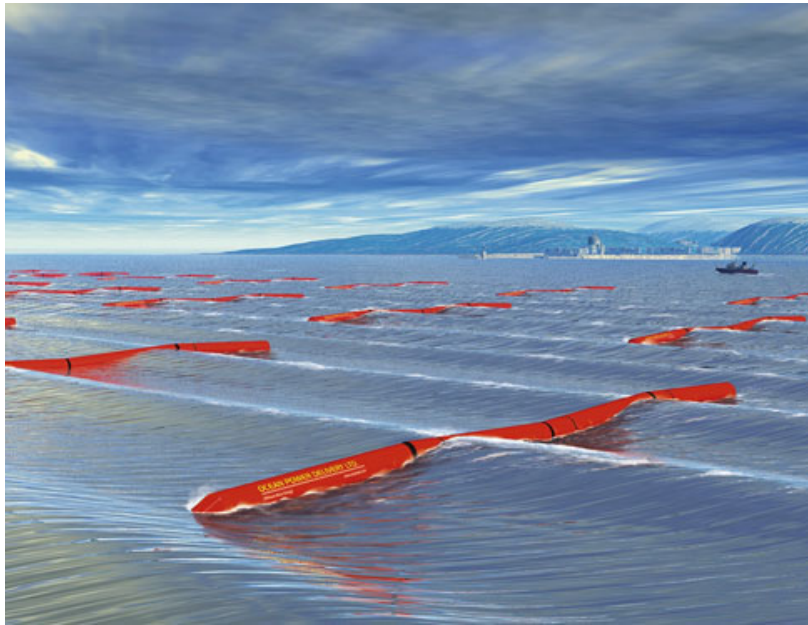

Fig. 2 Working principle of Attenuator (Pelamis) [25]

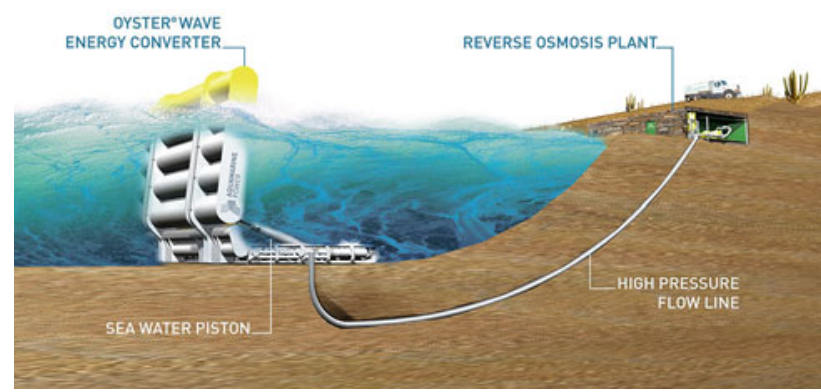

Fig. 3 Working principle of terminator (Oyster) [29]

Attenuator is a multiple-segment device floating parallel to the direction of the waves. The actuation mechanisms usually utilize the rotational motion at the joints of the segments. The varying heights of waves at each joint of the device will actuate the hydraulic pumps or other PTOs. One typical attenuator is Pelamis [24] (Fig. 2), which has the PTO system driven by hydraulic cylinders at the joints.

Terminator is floating device oriented perpendicular to the direction of the wave. The actuation mechanism is similar to Pelamis which uses the rotational induced waves. Typical terminators are the Oyster [26] (Fig. 3), Salter's Duck [27] and AFA's terminator [28].

\subsection{Oscillating water column (OWC)}

Unlike other OWECs, OWC is an indirect wave energy conversion device which can be near-shore or off-shore. By using the rise and fall of water within a chamber, the air inside the chamber is compressed or extended to actuate an air-driven turbine and generate electricity. There are shore-based OWCs such as: LIMPET 500 [30] (Fig. 4) and Pico [31]. Some other device, like Mighty Whale [32], is an OWC based device for offshore operation which is a combination of both point absorber and OWC.

\subsection{Wave overtopping}

Wave overtopping is another form of wave energy harvesting methodology. As Fig. 5 illustrates, a slope reflector will concentrate incoming waves and drive them into an elevated reservoir which is above the surrounding ocean. The power is then generated using low-head hydropower turbines when the water is released back to the ocean through a turbine outlet. The Wave Dragon [34] (Fig. 5) and Oceanlinx [35] are such typical examples while the Seawave Slot Cone generator [36] is another application with multiple reservoirs.

\section{Hydrodynamic characteristics for OWEC}

\subsection{Ocean wave formulation and assumptions}

Ocean wave energy is an indirect form of concentrated solar energy [2]. Solar radiation induced temperature and pressure difference creates wind and energy is transferred to wave by nonlinear wind-wave interactions [37]. Wind blows over ocean surfaces, leading to capillary waves, developed seas and eventually it gives swells, which can travel thousands of miles in deep water until dissipating their energy when they break on shore. Consequently, three factors, i.e. wind velocity, blowing duration and fetch, will affect the formation of ocean wave. A nomogram [38] in Fig. 6 for forecasting

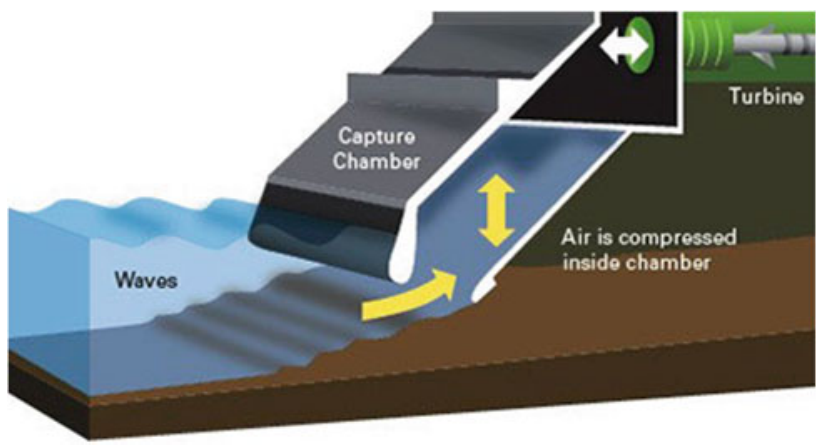

Fig. 4 Working principle of OWC [33]

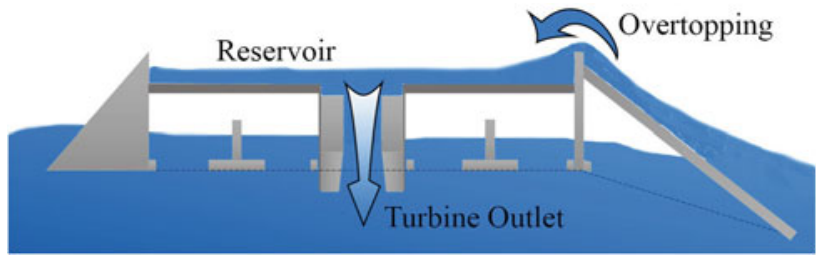

Fig. 5 Working principle of wave overtopping 
Fig. 6 A nomogram used for predicting the a peak wave frequency $T_{P}$ and $\mathbf{b}$ wave height $\sigma$ over different wind speed, fetch and duration time

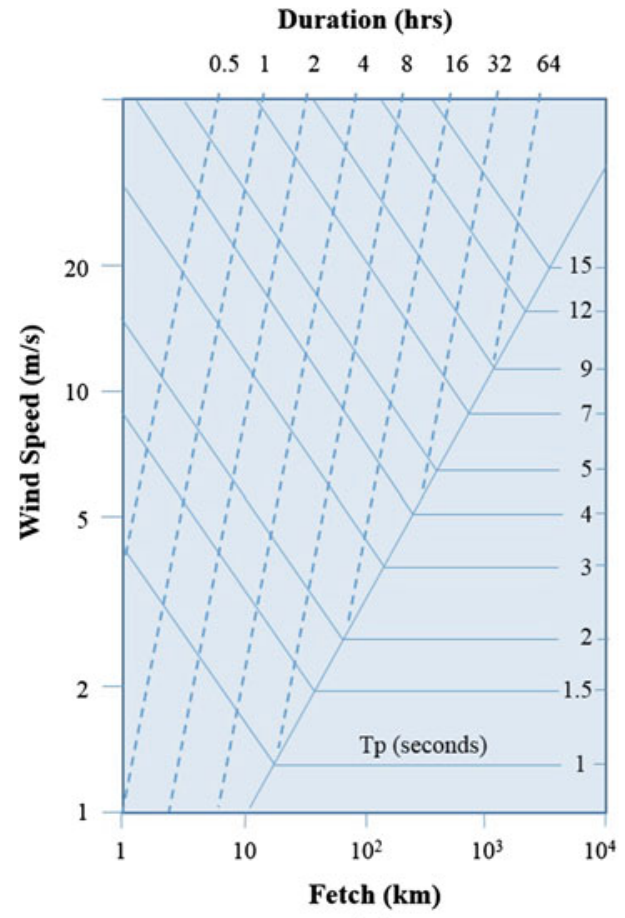

(a)

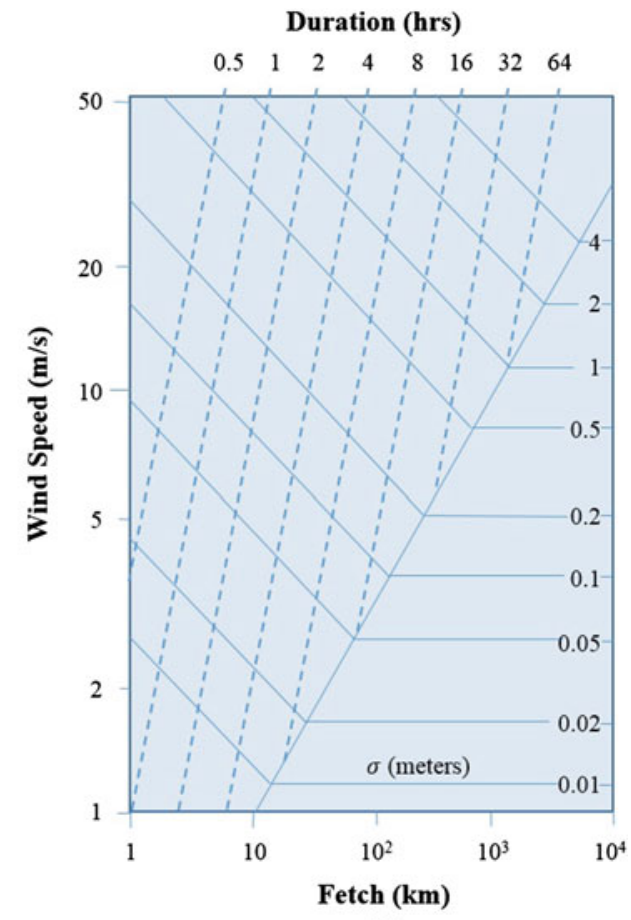

(b) peak wave period $T_{P}$ and wave height $\sigma$ in areas of restricted fetch can be helpful when we demand a quick estimation.

In real seas, the irregular ocean wave is not formed under certain law and thus it's hard to predict and utilize. Therefore, most of current researches are based on linear wave theory, i.e., Airy wave theory [39]. The elevation of ocean wave is expressed as

$\eta(x, y, t)=A \cdot \cos (k x \cos \beta+k y \sin \beta-\omega t)$,

where $\mathrm{x}$ and $\mathrm{y}$ are predefined axes of Cartesian coordinate system to describe the wave direction, $k$ is wave number, $\omega$ is the wave frequency, $A$ is the wave amplitude and $\beta$ is the propagation angle between wave direction and $\mathrm{x}$ axis. In deep water, due to the dependence of wave length $L$ on wave period $T$, we have the group celerity of linear wave:

$C=\frac{g T}{2 \pi} \sinh \left(\frac{2 \pi h}{L}\right)$.

Another crucial factor is wave height, which has a practical form given by:

$H_{i}=H_{0} \sqrt{\frac{2 \cosh ^{2}(k h)}{\sinh (2 k h)+k h}}$,

where $H_{0}$ is the deep water wave height, $k$ is wave number and $h$ is water depth.

The energy in ocean waves consists of kinetic energy associated with the orbital motion of the water particles and potential energy resulting from vertical displacement of the water surface away from the still water level. The rate at which energy is transmitted in the direction of wave propagation is the energy flux $P$ (also called wave power, in watts unit per crest wave width). With water density $\rho$, acceleration of gravity $g$ and wave height $H$, the energy flux $P$ is given by

$P=\frac{1}{16} \rho g H^{2} C\left(1+\frac{2 k h}{\sinh (2 k h)}\right)$.

To better evaluate the performance of OWEC, the term "capture width" is introduced. For an isolated body in three dimensions at a given frequency, this is defined as

$L=\frac{P_{c}}{P}$,

where $P_{c}$ is the total mean power absorbed by the OWEC and $P$ is the mean power per unit crest wave width of the incident wave train. Capture width can be interpreted as "efficiency" when it comes to two dimensions [40] to evaluate the experimental performance of devices. For example, the capture width for single oscillating OWEC, such as point absorber, is proved to be $\lambda / 2 \pi$. For attenuator or terminator, this value is proven to be $\lambda / \pi[41]$.

\subsection{Hydrodynamics for point absorber}

A floating body may move within six degrees of freedom under the interaction between the body and sea water: three rotational (pitch, roll and yaw) and three translational (heave, surge and sway). This is illustrated in Fig. 7.

When considering hydrodynamics and wave-buoy interaction in preliminary theoretical analysis, we usually consider 


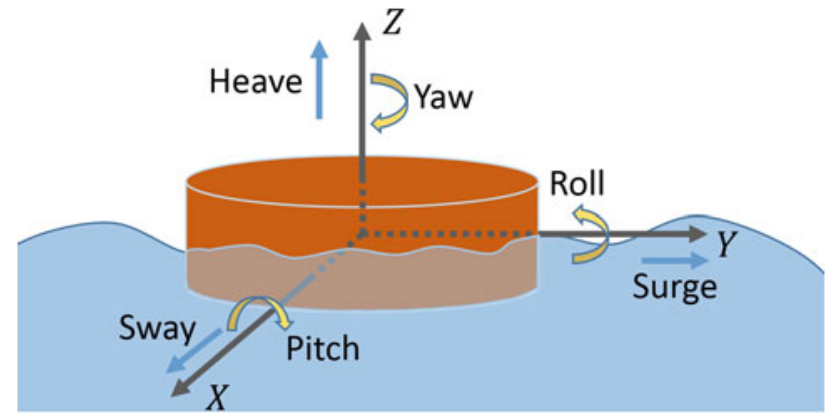

Fig. 7 Six motions of a floating body

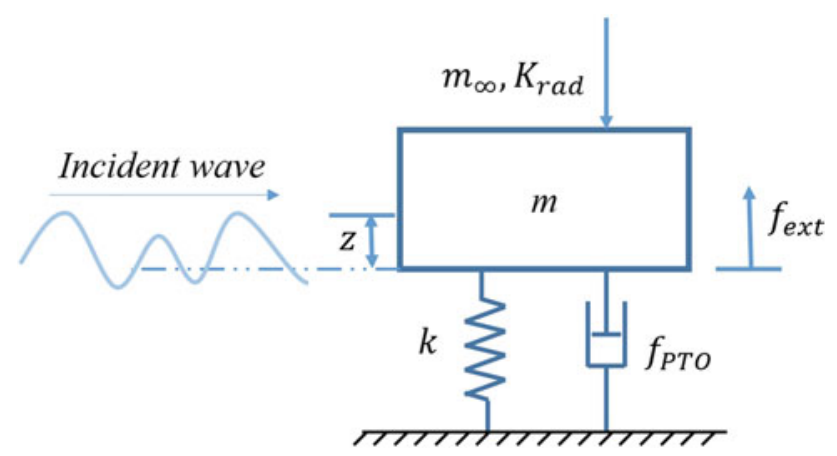

Fig. 8 Generalized dynamic model for single oscillating OWEC

its vertical motion and thus assume the wave is inviscid, incompressible and irrotational based on linear wave (Airy wave) theory. Figure 8 illustrates the general single oscillation model.

We can adopt the Eq. (6) in the time domain:

$\left(m+m_{\infty}\right) \ddot{z}+\int_{0}^{t} K_{\text {rad }}(t-\tau) \dot{z} d \tau+k z=f_{\text {ext }}+f_{\text {PTO }}$,

$\ddot{z}, \dot{z}$ and $z$ is the acceleration, velocity and displacement of the buoy the vertical direction (with $\mathrm{z}$ in calm water), respectively; $\mathrm{m}$ is the mass of the buoy; $\mathrm{m}_{\infty}$ is the added mass (limit value in infinite frequency) accounting for the inertia of the water surrounding the body; $k$ is the stiffness of the buoy induced by hydraulic restoring force, which is in proportional to the sea water density $\rho$ and the intercrossing surface of the buoy and sea water $S: k=\rho g S ; f_{P T O}$ is the force due to PTO; $f_{\text {ext }}$ is the excitation force due to incident wave, which can be obtained theoretically with linear wave theory or calculated by commercial software such as ANSYS-AQWA; $\int_{0}^{t} K_{\text {rad }}(t-\tau) \dot{z} d \tau$ accounts for the damping on the body due to energy transfer to waves radiated away, where $K_{\text {rad }}$ is the radiation impulse response which represents the radiation of waves generated by the buoy after an impulse at $t=0$.

The $\mathrm{m}_{\infty}$ and $K_{\text {rad }}$ can be obtained according to Cummin's decomposition [42]. $K_{\text {rad }}$ is originally approximated by a sum of complex exponential functions using Prony's method [43] as detailed by Duclos et al. [44] and can be done using the BEM code ACHIL3D [45]. $K_{\text {rad }}$ can also be obtained by

$K_{\text {rad }}(t)=\frac{2}{\pi} \int_{0}^{\infty} B(\omega) \cos (\omega t) d \omega$,

where $B(\omega)$ is the radiation damping coefficient, $\omega$ is the wave frequency [46]. Physically, $K_{\text {rad }}$ introduces a memory effect term with the convolution integral. Time domain Eq. (6) is good to describe the nonlinear system. However, the procedure of obtaining $K_{\text {rad }}$ is computation intensive and it is hard to apply control methods in standard simulation packages with Eq. (6), so different methods on state-space approximation of the time domain equation have been proposed, such as realization theory [47] and regression in frequency domain [48]. More specific reviews of floating body hydrodynamics within the diffraction regime and applicable OWEC modeling is introduced in $[49,50]$.

To give some physical insights to the point absorber OWEC, let us take a look at a simplified case where the hydrodynamic damping force is approximate as a viscous damping $b \dot{z}$ and the PTO force is assume to be linear $f_{P T O}=$ $c_{P T O} \dot{z}+k_{P T O}$. Then the whole dynamics system becomes linear, which can be written as:

$\left(m+m_{\infty}\right) \ddot{z}+\left(b+c_{P T O}\right) \dot{z}+\left(\rho g S+k_{P T O}\right) z=f_{\text {ext }}$.

And with a regular wave with a frequency $\omega$ and harmonic wave excitation force $f_{e x t}=F_{\text {ext }} e^{j \omega t}$, the oscillation amplitude in the frequency domain can be obtained as

$Z=\frac{F_{\text {ext }}}{\left(\rho g S+k_{P T O}\right)-\left(m+m_{\infty}\right) \omega^{2}+\left(b+c_{P T O}\right) j \omega}$.

The time averaged power extracted from the wave is [51,52]:

$P=\frac{1}{2} c_{P T O} \omega^{2}|Z|^{2}=\frac{1}{8 B} F_{\text {ext }}^{2}-\frac{B}{2}\left|i \omega Z-\frac{F_{\text {ext }}}{2 B}\right|^{2}$

which has the maximum value at

$\omega=\sqrt{\frac{\rho g S+k_{P T O}}{m+m_{\infty}}}$ and $c_{P T O}=b$.

These condition means that the buoy should have a resonance at the wave frequency and the damping of the PTO should equal to the hydrodynamic damping. Unfortunately, due to the size constraint the buoy frequency is typically much higher than the ocean wave frequency, and the hydrodynamic damping is generally not linear.

\subsection{Hydrodynamics for oscillation water column (OWC)}

OWC is similar to wind turbine due to its PTO and air flow activation source. The nonlinearities, which leads to 


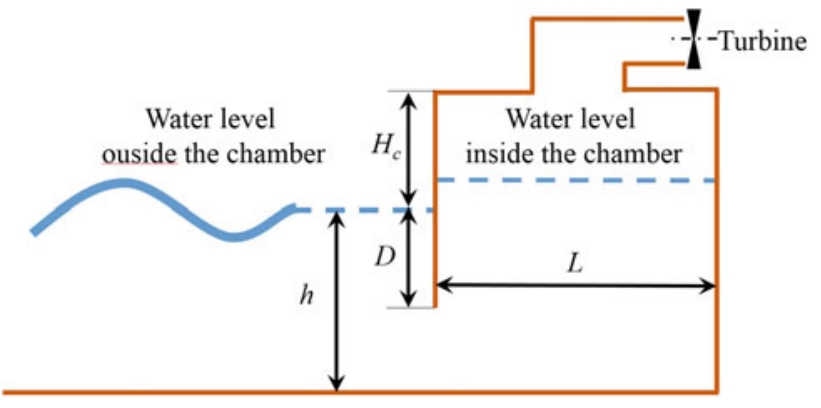

Fig. 9 Schematic of an OWC model introduced in Eq. (9)

complexity of control strategies, of both ocean wave and chamber air flow are overlapped in this typical OWEC. A stochastic formulation to evaluate the average performance of an OWC under the linear wave theory is introduced in [53] assuming the conversion from sea surface oscillations into air pressure oscillation is linear. The influence of such nonlinearity is considered in the absence of viscosity in [30]. Alves and Sarmento [54] investigated the influence of viscosity and turbulence via a " $k-\varepsilon$ " model. Numerous papers on this topic deal with the shore-based OWC at two dimensions. The increase in complexity in three dimensional analysis is significant. Nevertheless, two dimensional analysis can also provide important insights.

Most of the modeling of OWCs involving PTO assume the applicability of linear wave theory [16,34-36]. As Cruz [40] pointed out, linear wave based hydrodynamic analysis shouldn't be interpreted as a severe deficiency in preliminary modeling; the device must perform most efficiently in small waves. One representative linear modeling is proposed by Evans [55], who introduced the concept of an oscillating pressure patch on the water surface which is equivalent to the interior water surface of an OWC. According to his theory, the motion of the water free-surface inside the chamber displaces a volume-flow rate of air $q(\mathrm{t})$ and produces an oscillating air pressure $p(\mathrm{t})+p_{a}\left(p_{a}\right.$ is the pressure of atmosphere) due to the incident wave action and can be decomposed as

$q(\mathrm{t})=q_{d}(\mathrm{t})+q_{r}(\mathrm{t})$,

where $q_{d}(\mathrm{t})$ is the diffraction flow rate due to the incident waves if the internal pressure is kept constant and equal to $p_{a}$, and $q_{r}(\mathrm{t})$ is the radiation flow rate due to the oscillating air pressure in the absence of incident waves [53].

Another factor lies on the rate of change of the volume inside the chamber and can be represented by volume flux $Q$. To obtain a better understanding of the aerodynamics in the chamber, following the approach outlined originally in [56], a hydrodynamics and aerodynamics description regarding to a finite depth model (Fig. 9) is expressed as

$Q_{t}(t)=\frac{\rho_{\mathrm{c}}(t)}{\rho_{a}} Q(t)-\frac{\left[L\left(D+H_{c}\right) W-V_{w}(t)\right]}{\gamma p_{a}} \frac{d p}{d t}$,
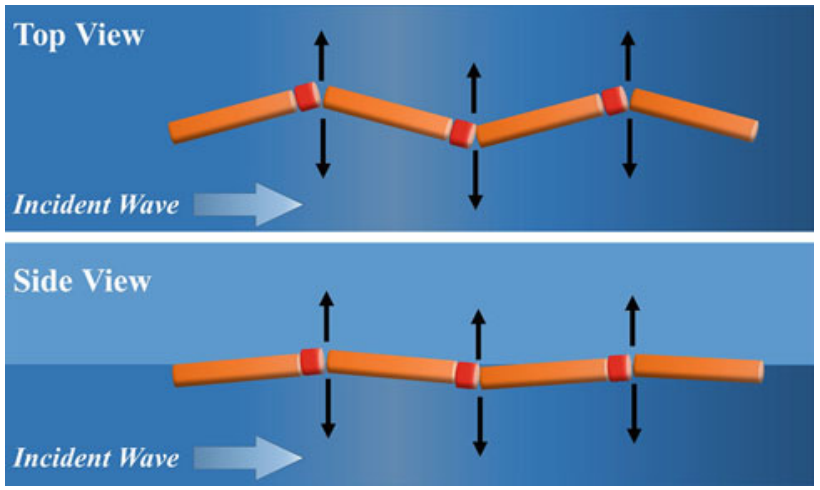

Fig. 10 Illustration of the motions of Pelamis OWEC

where $Q_{t}(\mathrm{t})$ is the volume flux at the turbine, $\rho_{c}(\mathrm{t})$ and $\rho_{a}$ are the density of the air inside and outside the chamber respectively, $L$ is the chamber length, $D$ is the width of the barrier, $H_{c}$ is the height of the chamber, $W$ is the arbitrary width which is time dependent, $\gamma$ is the usual ratio of specific heats [57]. $V_{w}(\mathrm{t})$ is the volume of water contained in the chamber. Such a model connects the water and air flow dynamics efficiently; however, some weak nonlinearity still exists but it can also be linearized based on certain assumptions for practical use.

\subsection{Hydrodynamics for attenuator}

The hydrodynamics of attenuator is of variety due to the designed geometry. Pelamis is a representative design and implementation of attenuator. Thus in this subsection we take Pelamis as an example to review the hydrodynamics of this type of OWEC.

Pelamis OWEC's segments are partially submerged, articulated structure composed of cylindrical sections linked by hinged joints at which PTOs are located. As Fig. 10 shows, the wave-induced motion of these joints is resisted by hydraulic rams which pump high pressure fluid through hydraulic motors via smoothing accumulators. The hydraulic motors drive electrical generators to produce electricity. Power is fed to the seabed via a single dynamic umbilical connected to a transformer in the machine's front tip.

Similar to other OWEC introduced above, Pelamis will achieve the maximum power absorption when it comes to resonance. Due to its significant weight, Pelamis has a large stiffness and thus the response to excitation wave is much faster than the incident wave. Thus, the resonance of Pelamis has to be achieved by reducing the stiffness of it. The geometry of the Pelamis joints is designed to dramatically reduce the stiffness of the system when desired through the following patented mechanism. Each of the four Pelamis power conversion segments allows motion about two perpendicular axes which are not horizontally or vertically oriented 


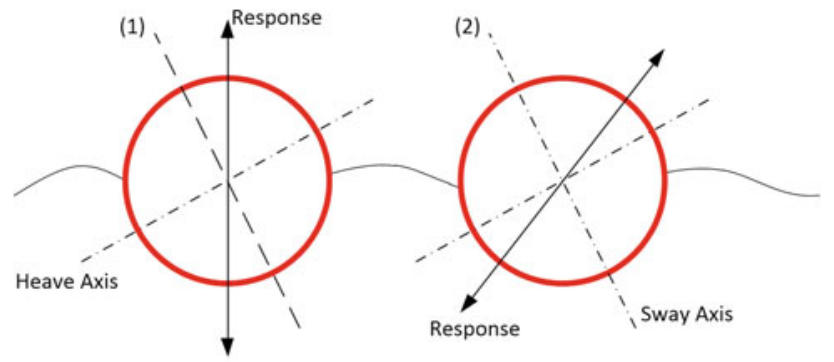

(a)

(b)

Fig. 11 a Non-resonant response and b resonant response of each Pelamis segment

Fig. 11. Instead, the axes are biased $25-30^{\circ}$ away from horizontal position to give an orthogonal pair of inclined axes of motion. The axis that allows motion in a more vertical direction is known as the heave axis, the axis that allows motion in a more sideways direction is known as the sway axis [40].

\subsection{Hydrodynamics for wave overtopping device}

Generally, wave overtopping is harmful to infrastructures and people. Therefore, most offshore structures are designed and to avoid overtopping. However, in the sense of energy harvesting, it's an inverse thinking to utilize overtopping to harvest ocean wave energy, which means these OWECs tend to maximize the overtopping. For some wave overtopping structures, we have approximate guidelines for the average rate and efficiency of overtopping of high crested structures [58] and simple geometry low-crested structures [59]. Usually, overtopping OWECs utilize the low-crested structure. Noticeably, such guidelines are based on theory and tested in laboratory and field scale. General method to model the power flows of overtopping wave energy converters is by computer simulation. According to a given probability distribution, a time series is constructed of the overtopping flow into the reservoir of the device [60].

Mathematically, Van der Meer and Janssen [59] proposed an exponential function model for wave overtopping at dikes, which provides theories for protecting the offshore structures against overtopping. This is shown in the following equation:

$\frac{q}{\sqrt{g H_{m 0}^{3}}}=\frac{0.067}{\sqrt{\tan \alpha}} \gamma_{b} \xi_{0} e^{-4.3 \frac{R_{c}}{H_{m 0}}\left(\frac{1}{\xi_{0} \gamma_{b} \gamma_{h} \gamma_{f} \gamma_{\beta}}\right)}$

where $q$ is the average wave overtopping discharge; $1 / \sqrt{g H_{m 0}^{3}}$ is the standard non-dimensionalizing factor for flow, using gravity acceleration $g$ and significant wave height $H_{m 0} ; \sqrt{\tan \alpha}$ is the slope; $\xi_{0}$ is the breaker parameter of wave; $R_{c} / H_{m 0}$ is the non-dimensional crest freeboard, which is the ratio between crest freeboard $R_{c}$ and significant wave height
$H_{m 0} ; \gamma_{b}, \gamma_{h}, \gamma_{f}, \gamma_{\beta}$ are the constants describing reduction factors for overtopping of the ramp.

This model can be also adopted for overtopping OWECs. One typical example, based on this work, is a formulae [58] for low crested two dimensional structures for Wave Dragon [34] in Eq. (15),

$$
Q_{N}=\frac{\bar{Q}}{W \lambda_{d r} \lambda_{\alpha} \lambda_{S} \sqrt{g H_{m 0}^{3}}}=0.2 e^{-2.6 \frac{R_{c}}{H_{m 0}}\left(\frac{1}{\gamma_{b} \gamma_{h} \gamma_{f} \gamma_{\beta}}\right)},
$$

where $Q_{N}$ is the non-dimensional flow; $\bar{Q} / W$ is the average flow $\bar{Q}$ unit of ramp width $W ; \lambda_{d r}$ is the reduction factor for energy passing beneath the draft of the ramp and $\lambda_{\alpha}$ is reduction factor for non-optimal slope defined in [58]; $\lambda_{S}$ is the reduction factor for low relative crest freeboard. This equation, as introduced in [58], provides an empirical result for overtopping rate with a set of parameters given and can be used for validating the overtopping measured from low crested two dimensional structures.

\section{Control strategies for point absorbers}

Explorations of controlling point absorber were evolved from regular waves to irregular waves. The point absorber has limited bandwidth in irregular waves compared to regular condition. Most of the control schemes of point absorber are designed to control the vertical motion and power flow to maximize the power absorption. Two widely used phase control methods, i.e. latching control and reactive control were proposed in literature to maximize the power absorption. In addition to these approaches, some other control methods, like declutch control and latching-operating-declutch control were. We will review the classical strategies and some modern strategies, like model predictive control (MPC).

\subsection{Latching control}

The natural frequency of the oscillating body is usually much higher than the frequency of the incident ocean wave due to design constraints. Thus, to achieve the maximum power harvesting, it is necessary to 'synchronize' the motion of the point absorber with the wave motion by lowering the frequency of the point absorber to force it approach the frequency of the incident wave. Then the point absorber will be in a quasi-resonant. Latching control is a discrete control method for this purpose and was first proposed by Budal and Falnes in 1980s. As Fig. 12 shows, latching control indeed plays as a controller to decrease the natural frequency of the oscillating body by latching the motion of the oscillating body when the its speed equals to zero, and release it when the phase of the velocity matches the phase of the predicted excitation wave. It's a passive control method thus it does 


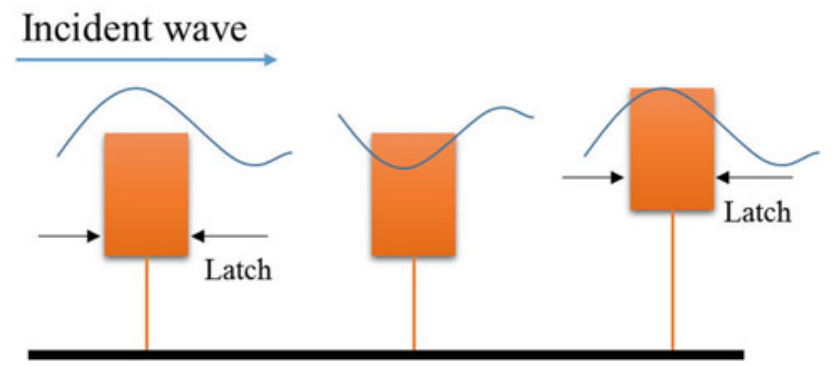

Fig. 12 Illustration of latching control

not need reactive power which means no extra power contribution is required to control the PTO force except the power to control the latching mechanism. Latching control can be implemented on OWEC by a friction latching mechanism for mechanical system [61] or a one-way valve for hydraulic system [62]. The prediction of oncoming incident wave can be realized by Kalman filter [63]. In this way, the heaving amplitude of oscillating body can be maximized and the energy absorbed is also maximized. For multi-degree of freedom systems, the application of latching control has shown to be more challenging; moreover, latching control may prove inadequate for arrays of point absorbers, since the optimum phase condition on which it is founded does not hold if more than one oscillators are present.

This method was further developed and applied on the single oscillating OWEC fixed to the bottom of the sea. Korde [64] applied this method to a device using an in-board active reference but in his research the latching control is exerted on the power take-off instead of the motion of the system. Babarit et al. [65] investigate a method that can be used to assess the benefit which can be brought by applying latching control on the relative motion of the single oscillating OWEC. Beirão et al. [66] verified the effectiveness of latching control by applying it to the Archimedes Wave Swing. Bjartelarsson and Falnes [67] also evaluated this method by experiments with a hydraulic PTO. A further step explored by Nolan et al. [68] is the optimal damping profiles for a heaving buoy OWEC based on latching control. They parameterized the damping term as a general sigmoid function:

$B(\mathrm{t})=\frac{B_{\max }-B_{\min }}{1+e^{-\beta\left(t-t^{*}\right)}}+B_{\min }$,

where $B_{\max }$ is upper boundary, $B_{\min }$ is lower boundary, $t^{*}$ is the time delay and $\beta$ is the slope. The sign of $\beta$ determines whether latching (negative) or declutching (positive) has to be applied. Such a function allows a certain range of possibilities for the damping profile (Fig. 13).

The control variable of latching control is actually the duration of latching. The instant of latching is imposed by the dynamics of the OWEC itself to make the damping infinite when the velocity of the OWEC dies to zero. After latching

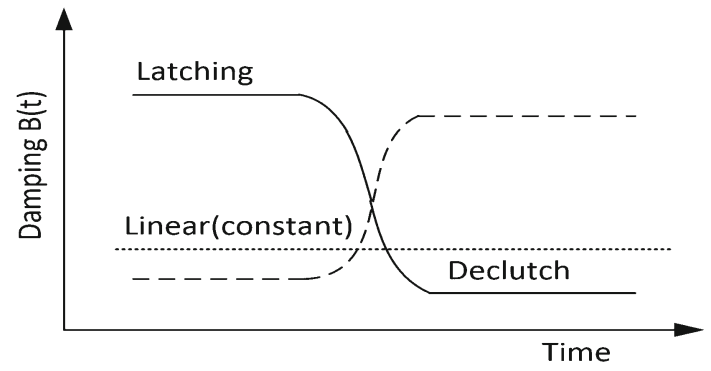

Fig. 13 Possible damping profiles for latching control [48]

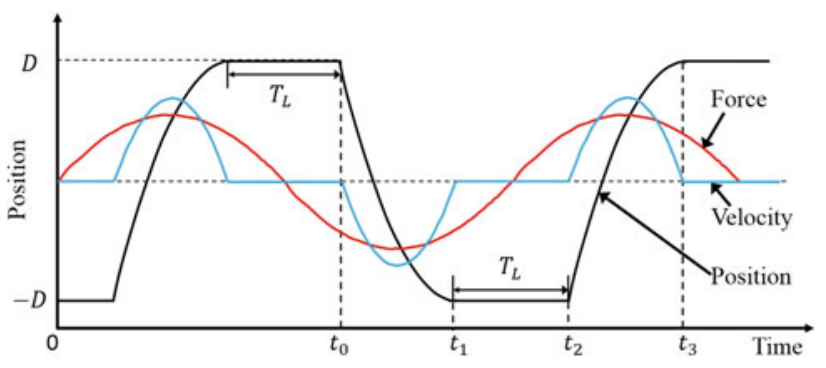

Fig. 14 Latching calculations

duration, the finite damping value reached after releasing the device, has to be chosen by considering energy absorption versus design limitations on the amplitude of the oscillation of the OWEC. Ringwood and Butler [69] proves that the choice of damping value has insignificant effect on the optimum latched time period. Thus, the single and most crucial control variable, for a point absorber system employing a latching strategy, becomes the latching duration $T_{L}$. It can be evaluated from Eq. 17 and the dynamic response period is illustrated in Fig. 14,

$T_{1}-T_{0}=T_{3}-T_{2}=\frac{T_{\Omega}}{2}-T_{L}$,

where $T_{\Omega}$ is the period of incoming waves which, as mentioned above, can be predicted via methods like Kalman filter.

\subsection{Declutch control}

Declutching was introduced as a "freewheeling" by Salter et al. [70] and Wright et al. [71]. Babarit et al. [72] investigated more details into this methodology and precisely described that declutch control can assess the energy capture width of a point absorber efficiently. Unlike some sea state dependent control method like the one introduced by Falcão [73] as pseudo-continuous control, declutch control is comparatively easier to implement without complexity. It needs only a by-pass valve in the circuit of the hydraulic cylinder and later it's applied to the SEAREV wave energy converter [22] under regular and irregular sea states to demonstrate its advantages theoretically [72]. 


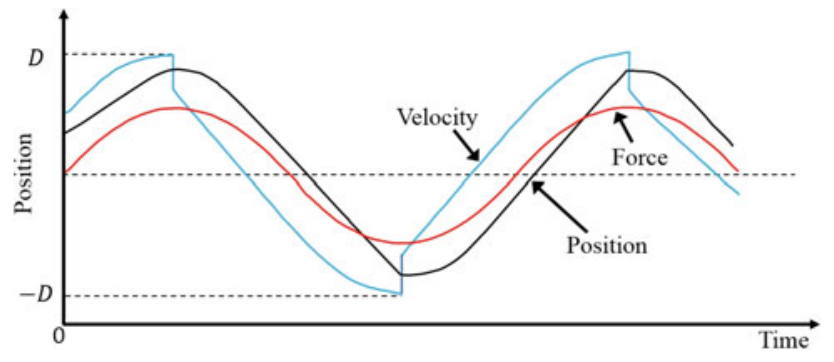

Fig. 15 Declutch calculations

Like latching control, declutch control is also a discrete method to achieve maximum power harvesting. The difference between latching control and declutch control is that declutch control is applied on the PTO rather than the oscillating body. Unlike latching, declutching corresponds to a positive value of the slope of the damping profile. Figure 15 shows the force and position characteristics of the declutching [68]. Similar to latching control, it's proved that the prediction of the future knowledge of the excitation force is still an issue when irregular sea states are considered [72].

When latching control takes effect, the damping of the oscillating body switches from a constant value to a very large value or even literally infinite, i.e. $C_{O W E C}=C_{0} \rightarrow$ $\left(C_{0}+\infty\right)$ while declutch control is working, the damping of the PTO is switched from a constant value to zero, i.e. $C_{P T O}=C_{0} \rightarrow 0$. Babarit et al. [72] derived the expression for the control criteria of declutch control for a hydraulic OWEC:

$u_{c}= \begin{cases}1, & \text { if } \operatorname{sign}(\dot{z}) \mathrm{h}(X)>0 \text { and }|\dot{z}|>0 \\ 1, & \text { if } \operatorname{sign}\left(F_{h, g}\right) \mathrm{h}(X)>0 \text { and }|\dot{z}|=0 \\ 0, & \text { else }\end{cases}$

where $u_{c}$ is the control variable which is set to 1 when the PTO is fully operating and set to 0 when the PTO disengages and discontinues working. $\dot{z}$ is the component of the velocity vector of the cylinder; $F_{h, g}=-F_{P T O}$ (the force acting on the PTO); $\mathrm{h}(\mathrm{X})$ is a scalar function where $\mathrm{X}$ is a state vector (it takes displacement, velocity, volume, pressure and radiation damping into account).

\subsection{Latching-operating-declutch (LOD) control}

Besides latching and declutch control, Babarit and coworkers [74] also further developed a method utilizing both latching and declutch control based on a two degree of freedom (Fig. 16) oscillation system on which latching control is applied on the OWEC while declutch control is applied on the PTO. It is stated that this integrated methodology can achieve much higher energy extraction than using only latching or declutch control.

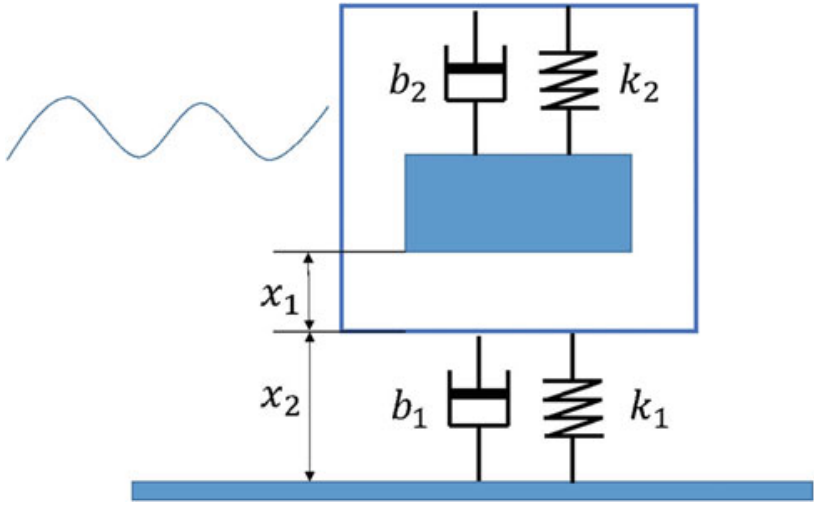

Fig. 16 Point absorber style OWEC with two degrees of freedom

The control strategy adopted two control variables $u_{1}$ and $u_{2}$, which have the following expression respectively:

$G(\mathrm{t})+\tau_{\text {latching }} \dot{G}(\mathrm{t})=u_{1} G_{0}$

$b_{2}(\mathrm{t})+\tau_{\mathrm{PTO}} \dot{b}_{2}(\mathrm{t})=u_{2} B_{0}$.

Equation (19) is for latching control and $u_{1} \in[0,1]$ is the control variable. When the controller is at latching mode, the control variable $u_{1}$ is set to 1 , and $G(\mathrm{t})$, a latching coefficient defined in a simplified modelling of latching force:

$f_{\text {latching }}=-u_{1} G\left(m_{2}+m_{\infty}\right) \dot{z}_{2}$

grows exponentially to its final value $G_{0}$ with a time constant $\tau_{\text {latching. }}$. The $\tau_{\text {latching }}$ represents the time delay in the response of the real actuators. When controller switches back to operating mode, $u_{1}$ is reset to 0 .

Likewise, Eq. (20) describes declutch mode with a control variable $u_{2}$ switching from 1 to 0 when declutch mode is activated. Thus the damping of the PTO decays to 0 exponentially.

The overall expression of the control strategy is given by:

$\begin{cases}u_{1}=1, \quad \forall u_{2}, & \text { system latched } \\ u_{1}=u_{2}=0, & \text { system operating } \\ u_{1}=0, u_{2}=1, & \text { system declutched. }\end{cases}$

It was proved that latching-operating-declutch control is a strategy that leads to the largest increase in energy absorption, with gains up to $500 \%$. It was also pointed out that LOD control is relatively insensitive to the value of the PTO damping coefficient, even if large values of it seem to marginally improve the amount of absorbed energy. However, for some problems, how to verify the feasibility and efficiency of this method experimentally still needs to be addressed.

\subsection{Reactive control}

Reactive control, in principle, is implemented by a reactance force provided by its PTO to balance the intrinsic impedance 
(determined by stiffness, inertia and damping) of the overall OWEC, and hence the system will achieve an optimum condition to absorb maximum energy. Because its controller can work all the time it is categorized as a continuous control. In Salter's Duck design [75], it used reactive control and provided a reactive force in proportion to its angular displacement and acceleration. Korde [76] found that in reactive control, velocity feedback could be used to adjust the damping of the PTO to balance the radiation damping of the OWEC to enable maximum permissible energy absorption. Optimal power absorption requires that the converter feels no reactive force (as at resonance) and that the energy absorption rate (damping) equals to the rate at which kinetic energy is being radiated from the device. Reactive control is comparatively simple for regular waves because the composition of wave is invariant. However, for irregular waves, reactive control seems to be of difficulty due to the requirement for prediction of measured signals into the future and subsequent time-consuming calculation which may raise problems to real-time control.

Another disadvantage may also be mentioned. Since the PTO needs to provide energy to cancel the intrinsic impedance which is significant sometimes, this means energy flow may be inversed from OWEC to energy storage, i.e. part of the harvested energy will be consumed to provide the reactance force [77]. Thus, for a low energy conversion efficiency system, especially for narrow capture width OWECs like point absorber, reactive control may not be a good plan; for future high energy conversion efficiency system or wide capture width, this control method will be found to be more significant. Actually, Falcão et al. [78] conducted a comparison between discrete latching control and continuous reactive latching on an IPS buoy [79]. It was found that latching control is easy to implement and make use of while reactive phase control can hardly be achieved in an effective way.

\subsection{Model predictive control (MPC)}

The theories of MPC were introduced in 1970s and also known as receding horizon control or open loop feedback optimization [80]. MPC theories have been advanced and the computational capability of control units has increased tremendously so that today's MPC applications are used in various technical control problems. Its advantages, including multivariable control capability, input and output time delay handling, convenience of enforcing various constraints, etc., boost its wide applications. The core components of MPC are the prediction model formulation, objective function establishment and corresponding optimizing algorithm. The working principle of this methodology is demonstrated in Fig. 17: current control signal is obtained by solving a finite horizon open loop optimal control problem by minimizing an objective function online at each time step [81].

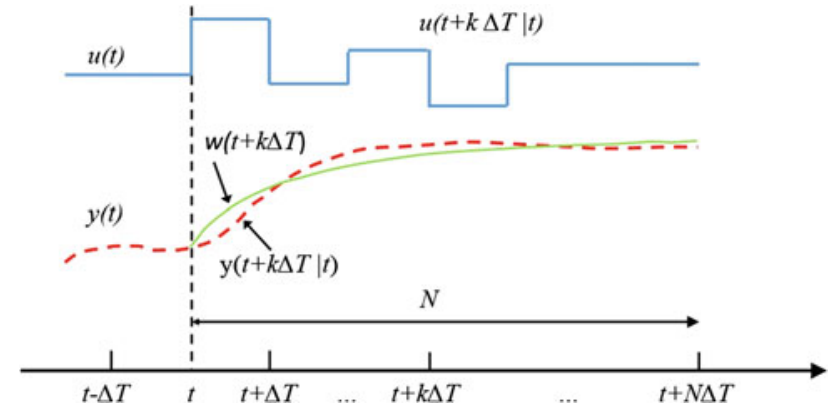

Fig. 17 Working principle of MPC

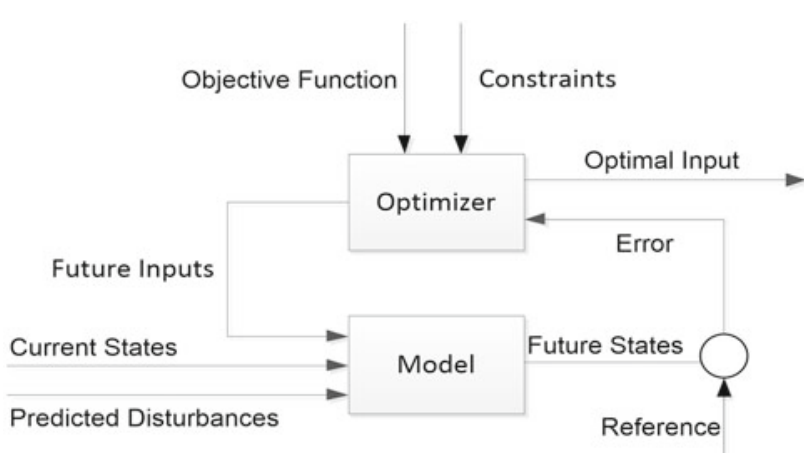

Fig. 18 Overall structure of MPC

Then the current system state is used as the initial state for the model. This yields a sequence of optimal control signals at every time step, where only the first signal is applied to the process. Also, the prediction horizon is shifted to the next time step before the new optimization starts. A typical MPC [82] structure requiring a reference, namely an optimal velocity reference trajectory which the actual velocity has to follow in order to achieve optimal energy capturing is shown in Fig. 18.

Application on MPC is abundant. The MPC control for one body point absorber without velocity reference and twobody point absorber is comprehensively introduced in [82]. Gieske [83] adopted an MPC technique and numerical study to Archimedes Wave Swing, then developed a controller that maximizes the energy conversion within constraints set by the machinery and its auxiliaries with this method. Hals et al. [84] introduced an MPC method to a heaving buoy OWEC. The main idea is to optimize the expected response of the system over a short future horizon using a discrete time model of the conversion unit and a prediction model of the input force using Kalman filter. The maximization of power output with the chosen constraints becomes a quadratic programming optimization problem. Bacelli et al. [85] combines MPC and dynamic programming [86] for the control of a nonlinear point absorber system dedicated to potable water production. 


\subsection{Other modern control methods}

With the great enhancement of computational capability, some modern control methods on point absorbers are focusing on forming the energy harvesting procedure as an optimization problem.

Li et al. [87] presented a method combining deterministic sea wave prediction (DSWP) and constrained optimal control to obtain high energy conversion efficiency for a point absorber using hydraulic or electromagnetic PTO. They formulated the optimization problem as a dynamic programming problem to find the optimum for bang-bang control and thus, achieve the maximum energy harvesting. Given a strong wave predicting capability (up to tens of seconds), it is reported this method can achieve up to twice of the energy output compared to control schemes which aren't using DSWP.

Genetic Algorithm (GA), which is well-known in optimization, is also adopted in controlling an OWEC. For instance, it is used in [88] to tune the damping and stiffness of the OWEC so that the oscillating body will be in the resonant heaving motion all the time. Then the maximal energy will be converted to electricity.

See et al. [89] introduced a bio-inspired method named Ant Colony Optimization metaheuristic, which is one of the global optimization algorithms. This method is used to assist deciding parameters of a PTO controller in real-time by defining an objective function and constraints according to sea states and OWEC configuration. It's reported that this method will reach the optimal control parameter within a short interval so it would be suitable for controlling OWEC at continuous changing real sea states.

It can be observed that the above exemplified control methods rely on the computational capability. With the development of modern computational units, it can be seen that these methods will be more advanced and mature for fast controlling and managing power harvesting in real-time.

\section{Control strategies for attenuators}

The motion control for attenuator (like Pelamis) or terminator is different from other kinds of OWEC since its dominant motion is rotation while others are mainly translation. The offset angle of the joints sets the resonant frequency for the Pelamis by determining its angle of motion with respect to the water surface when it is oscillating freely. This can be chosen to match the dominant wave climate [12]. When the motion is damped, the angle of motion is determined by the ratio of PTO damping coefficients in the two orthogonal degrees of freedom [24]. This changes both the excitation and radiation hydrodynamic coefficients.

Pelamis also implements control to alignment its body with respect to the principal wave direction passively. This approach tends to limit forces rather than increase power, as the Pelamis is designed to operate in attenuator configuration. Besides, PTO force control is also implemented. Once the required ratio of the PTO damping coefficients in the two orthogonal joints is decided, the concept of impedance matching is used as a basis to decide the required PTO moments. Transducer measurements of any joint parameter, such as angle or angular velocity, can be used to choose the desired PTO settings. Parameters are in fact changed on a slow time-scale. However, details of the method for the PTO settings are not published.

The moment levels are actuated by choosing the number of cylinders in the pump that are open at any time. These cylinders are opened with electronically controlled valves. In the power maximization regime, the resulting moment [12] contains too many harmonics to conform to many definitions of linearity, so time-domain simulations are used to model real-time response. Nevertheless, the linear modeling may be useful in some instances. Frequency domain analysis was used to develop the Pelamis both mechanical and control design [14].

In Pelamis, power regulation is also implemented. The generator voltage is kept as smooth as possible. Changes to (peak) voltage are made using a slow ramp. Excess power is dumped using resistive heating [90].

\section{Control method for oscillating water column (OWC)}

\subsection{Control concepts}

Similar to linear wave theory based control strategies for point absorber, current OWC control strategies are under the linear potential flow theory [91]. The maximum power absorption is achieved when the inner chamber pressure can be kept in phase with the wave diffraction flow. From this point of view, latching control is also feasible for OWCs. One strategy is designing a controller to calculate the optimum air pressure as a control output by measuring the incident wave and obtaining the error between incident wave and radiated wave, meanwhile, the computation and prediction of excitation volume flux is required. Another control strategy is based on measuring the inner air chamber pressure and, similarly to the first strategy, it needs to compute the optimum air pressure as the control output [56]. An alternative classification in [92] characterizes the management of floating height is described as slow control, which aims to tuning the device to sea state within hour scale by pumping air into open bottomed chambers. The use of data collected upstream to give forewarnings to aid reservoir management is described as fast control, which can drive the device to follow current waves within minute scale to harvest most energy. 


\subsection{Discrete control}

Discrete on-off control can also be implemented on OWC type and several early explorations have been made [93,94]. It is achieved by switching air valves of the pneumatic PTO. Although the motion cannot be completely locked, the switching operation of the valves has an influence on the oscillatory motion. Optimum oscillation for maximum absorbed power may be approached in this way somehow [77]. Moreover, an OWC control research area named throttle valve control is introduced in [95]. Since the turbine acts as a damping element to the OWC, the throttle valve of OWC can be controlled to prevent stall and allow operation in high sea states and meanwhile, the valve position also affects damping. Thus the damping can be tuned to an optimal value by controlling the throttle valve. It is also suggested to investigate the control of variable pitch turbine blades to optimize efficiency and adjust damping [95].

\subsection{Time synchronizing control}

The turbine in an OWC is typically a self-rectifying turbine or a conventional turbine in conjunction with check valves. The self-rectifying turbine allows the generator operating in unidirection regardless the air inhaling or exhaling inside the chamber. The most commonly used rectifying turbine in this application is the Wells turbine.

Nunes et al. [96] explored an OWC phase control based on the variable pitch Wells turbine. Due to the turbine's dual role as a compressor and as a turbine, the phase control of the internal pressure becomes possible. Also, as Falcao [97] pointed out that optimum phase control of an OWC is a non-causal problem, the suitable controller should be predictive. They presented an energy quality control to provide prediction which works with a fixed length time window. The controller follows a ramp reference which is the integral of the power predicted to be absorbed during the chosen time window.

Practically, Chatry et al. [98] presented a study assuming the ability to control the air flow rate across the turbine according to a feedback of the pressure in the chamber. However, the transfer function of the corresponding controller can be derived in the frequency domain but not in the time domain, thus the practical implementation becomes unreachable. Thus, they proposed a self-adaptive strategy implemented in a fully nonlinear numerical wave tank based on the on-line tuning of the regulator with the help of an instantaneous frequency estimated by an augmented Kalman filter.

\section{Conclusions}

The long historical interest and investigation on ocean wave yields numerous technologies and principles for OWECs. As a significant part in harvesting wave energy, dynamics and controls play important roles. In this review, the mainstream OWECs and their working principles as well as the hydrodynamics of OWECs are briefly introduced first. Then we surveyed various control strategies and their pros and cons. Since point absorber is widely adopted for OWEC (due to its high flexibility and efficiency), the researches on control methods for point absorbers are more extensive than other type of OWECs. Attenuator is not so common but it still has Pelamis, the first utility-scale OWEC, as a typical representative OWEC in this category. It may take some time to develop good control strategies for attenuator and evaluate their efficiency in the long run. OWC is another popular form of OWEC. Its control strategies also experienced a prosperous time but they have less variation compared to point absorbers due to their similar structure and PTOs. Wave overtopping is less complicated in structure and the control strategies are far less introduced in literatures. Thus it's not reviewed specifically in this paper.

Ocean wave energy harvesting is a clean, emission-free and environment-friendly procedure compared to conventional energy conversion technologies. It is being recognized that ocean wave energy conversion is one of the promising renewable energy technologies together with wind and solar energy. The further challenges in ocean wave energy conversion may arise from large scale verification, the arrayed OWEC control, and grid-tied OWEC control. Small-scale OWECs have been proven to be economic, efficient and reliable. When we come to large scale or grid-tied OWECs, more technological details should be investigated and addressed, especially the control strategies from a single converter implementation to arrayed OWECs, long-term operation, and maintenance management.

Acknowledgments The work is partially supported by SUNY/RF Research Collaboration Fund and SBU-BNL Seed Grant.

\section{References}

1. Boud R (2003) Status and research and development priorities, wave and marine current energy. UK Department of Trade and Industry (DTI), DTI report \# FES-R-132, AEAT report \# AEAT/ENV/1054

2. EPRI (2011) Mapping and assessment of the United States ocean wave energy resource, Palo Alto, CA

3. ChuanKun W, Shi W (2008) The ocean resources and reserves evaluation in China. In: 1st National symposium on ocean energy, Hangzhou, China, pp 169-179

4. Zhang D, Li W, Lin Y (2009) Wave energy in China: current status and perspectives. Renew Energy 34:2089-2092. doi:10.1016/ j.renene.2009.03.014 
5. Rodrigues L (2008) Wave power conversion systems for electrical energy production. In: International conference on renewable energies and power quality

6. Muetze A, Vining JG (2006) Ocean wave energy conversion-a survey. In: Conference record of the 2006 IEEE industry applications conference forty-first IAS annual meeting (IEEE), pp 1410 1417

7. Ross D (1995) Power from the waves. Oxford University Press, Oxford

8. McCormick ME (1981) Ocean wave energy conversion. Wiley, New York

9. Grove-Palmer COJ (1982) Wave energy in the United Kingdom: a review of the programme June 1975 to March 1982. In: Proceedings of the 2nd international symposium on wave energy utilization, Trondheim, Norway, pp 23-54

10. Ocean Renewable Energy Coalition (2011) U. S. marine and hydrokinetic renewable energy roadmap. Power 1-30

11. Falcão AFDO (2010) Wave energy utilization: a review of the technologies. Renew Sustain Energy Rev 14:899-918. doi:10.1016/j. rser.2009.11.003

12. Henderson R (2006) Design, simulation, and testing of a novel hydraulic power take-off system for the Pelamis wave energy converter. Renew Energy 31:271-283. doi:10.1016/j.renene.2005.08. 021

13. Cargo CJ, Plummer AR, Hillis AJ, Schlotter M (2011) Determination of optimal parameters for a hydraulic power take-off unit of a wave energy converter in regular waves. Proc Inst Mech Eng A 226:98-111. doi:10.1177/0957650911407818

14. Mei CC (2012) Hydrodynamic principles of wave power extraction. Philos Trans A 370:208-234. doi:10.1098/rsta.2011.0178

15. Heath TV (2012) A review of oscillating water columns. Philos Trans A 370:235-245. doi:10.1098/rsta.2011.0164

16. Delauré YMC, Lewis A (2003) 3D hydrodynamic modelling of fixed oscillating water column wave power plant by a boundary element methods. Ocean Eng 30:309-330. doi:10.1016/S00298018(02)00032-X

17. Salter SH (1989) World progress in wave energy-1988. Int $\mathbf{J}$ Ambient Energy 10:3-24. doi:10.1080/01430750.1989.9675119

18. Li Z, Zuo L, Kuang J, Luhrs G (2013) Energy-harvesting shock absorber with a mechanical motion rectifier. Smart Mater Struct 22:025008. doi:10.1088/0964-1726/22/2/025008

19. Ocean Power Technologies Inc (2009) Making waves in powerannual report of ocean power technology

20. Weinstein A, Fredrikson G, Jane M et al (2003) AquaBuOY-the offshore wave energy converter numerical modeling and optimization. OCEANS04 MTTSIEEE TECHNOOCEAN04 4:1854-1859

21. Weber J, Costello R, Mouwen F et al (2010) Techno-economic WEC system optimisation-methodology applied to Wavebob system definition. In: 3rd International conference on ocean energy (ICOE)

22. Josset C, Babarit A, Clément AH (2007) A wave-to-wire model of the SEAREV wave energy converter. Proc Inst Mech Eng M 221:81-93. doi:10.1243/14750902JEME48

23. De Sousa Prado MG, Gardner F, Damen M, Polinder H (2006) Modelling and test results of the Archimedes wave swing. Proc Inst Mech Eng A 220:855-868. doi:10.1243/09576509JPE284

24. Pizer DJ, Retzler C, Henderson RM et al (2005) Pelamis WECrecent advances in the numerical and experimental modelling programme. In: Proceedings of 6th European wave tidal energy conference, pp 373-378

25. EERE (2008) World's first wave energy project goes commercial. http://apps1.eere.energy.gov/news/news_detail.cfm/ news_id=12039

26. Whittaker T, Folley M (2012) Nearshore oscillating wave surge converters and the development of Oyster. Philos Trans A 370:345364. doi:10.1098/rsta.2011.0152
27. Salter SH (1974) Wave power. Nature 249:720-724

28. Siegel SG, Jeans T, McLaughlin TE (2011) Deep ocean wave energy conversion using a cycloidal turbine. Appl Ocean Res 33:110-119. doi:10.1016/j.apor.2011.01.004

29. AlphaGalileo Foundation (2009) Harnessing wave power with new "Oyster" machine. ScienceDaily. http://www.sciencedaily. com/releases/2009/07/090730073928.htm. Accessed 13 Jun 2013

30. Mingham C, Qian L, Causon D et al (2003) A two-fluid numerical model of the Limpet OWC. In: 5th European wave energy conference, Cork, Ireland, pp 119-125

31. Neumann F, Winands V, Sarmento AJNA et al (2008) Pico shoreline OWC?: status and new perspectives. In: Proceedings of the 2nd international conference on ocean energy (ICOE), Brest, France, pp 1-7

32. Osawa H, Washio Y, Ogata T, Tsuritani Y (2002) The offshore floating type wave power device "mighty whale" open sea tests. In: The twelfth (2002) international offshore and polar engineering conference

33. Stauffer NW (2009) Capturing the energy in ocean waves. http:// mitei.mit.edu/news/capturing-energy-ocean-waves. Accessed 12 Jun 2013

34. Kofoed JP, Frigaard P, Friis-Madsen E, Sørensen HC (2006) Prototype testing of the wave energy converter wave dragon. Renew Energy 31:181-189. doi:10.1016/j.renene.2005.09.005

35. Leary D, Esteban M (2009) Climate change and renewable energy from the ocean and tides: calming the sea of regulatory uncertainty. Int J Mar Coast Law 24:617-651. doi:10.1163/ 092735209X12499043518269

36. Kofoed JP (2005) Model testing of the wave energy converter seawave slot-cone generator. Aalborg University, Aalborg

37. Herterich K, Hasselmann K (2006) A similarity relation for the nonlinear energy transfer in a finite-depth gravity-wave spectrum. J Fluid Mech 97:215. doi:10.1017/S0022112080002522

38. Donelan M (1980) Similarity theory applied to the forecasting of wave heights periods and directions. In: Proceedings of the Canadian coastal conference, National Research Council of Canada, pp $47-60$

39. Komar PD, Gaughan MK (1973) Airy wave theories and breaker height prediction. In: Proceedings of the 13th coastal engineering conference (ASCEM), pp 405-418

40. Cruz J (2008) Ocean wave energy-current status and future perspectives. Springer, Berlin

41. Newman JN (1976) The interaction of stationary vessels with regular waves. In: Bishop RED, Parkinson AG, Price W (eds) The 11th symposium on naval hydrodynamics. Mechanical Engineering Publications Limited, London, pp 491-501

42. Cummins W (1962) The impulse response function and ship motions. Schiffstechnik 9:101-109

43. De Prony BR (1795) Essai Expérimental et Analytique sur Les Lois de la Dilatabilité Des Fluides Élastiques et sur Celles de la Force Expansive de la Vapeur de L'eau et de la Vapeur de L'alcool À Différentes Températures. Ecole Polytech 1:24-76

44. Duclos G, Clément AH, Chatry G (2000) Absorption of outgoing waves in a numerical wave tank using a self adaptive boundary condition. Int J Offshore Polar Eng 11:168-175

45. Clément AH (1999) Using differential properties of the green function in seakeeping computational codes. In: Proceedings of the $3 \mathrm{rd}$ international conference on numerical ship hydrodynamics, vol 6 , pp 1-15

46. Falnes J, Perlin M (2003) ocean waves and oscillating systems: linear interactions including wave-energy extraction. Appl Mech Rev 56:B3. doi:10.1115/1.1523355

47. Kristiansen E, Hjulstad A, Egeland O (2006) State-space representation of radiation forces in time-domain vessel models. Model Identif Control 27:23-41. doi:10.4173/mic.2006.1.2 
48. Pintelon R, Schoukens J (2012) System identification. doi:10.1002/ 9781118287422

49. Wehausen JV (1971) The motion of floating bodies. Annu Rev Fluid Mech 3:237-268

50. Jefferys ER (1980) Device characterisation. In: Count B (ed) Power from sea waves based on the proceedings of a conference on power from sea waves. Academic Press Inc., New York, pp 413-438

51. Evans DV (1980) Some analytic results for two and three dimensional wave-energy absorbers. Power Sea Waves 213:213-249

52. Evans DV (1979) Some theoretical aspects of three-dimensional wave-energy absorbers. In: Symposium on ocean wave energy utilization

53. Falcão A (2002) Stochastic modelling of OWC wave power plant performance. Appl Ocean Res 24:59-71. doi:10.1016/S01411187(02)00022-6

54. Alves M, Sarmento A (2005) Non-linear and viscous diffraction response of OWC wave power plants. In: 6th European wave and tidal energy conference, pp 11-17

55. Evans DV (1982) Wave-power absorption by systems of oscillating surface pressure distributions. J Fluid Mech 114:481-499. doi:10. 1017/S0022112082000263

56. Sarmento A, Gato L, Falcão AdO (1990) Turbine-controlled wave energy absorption by oscillating water column devices. Ocean Eng 17:481-497

57. Dixon SL (2010) Fluid mechanics and thermodynamics of turbomachinery. J Endocrinol Investig 10(Suppl 4):459

58. Kofoed J (2002) Wave overtopping of marine structuresutilization of wave energy. Aalborg University, Aalborg

59. Van der Meer JW, Janssen JPFM (2002) Technical report: wave run-up and wave overtopping at dikes. In: Wave forces on inclined and vertical wall structures, $\mathrm{p} 43$

60. Tedd J, Kofoed JP (2009) Measurements of overtopping flow time series on the wave dragon, wave energy converter. Renew Energy 34:711-717. doi:10.1016/j.renene.2008.04.036

61. Budal K (1981) Model experiment with a phase-controlled point absorber. In: Second international symposium on wave tidal energy, pp 191-206

62. Budal K, Falnes J (1980) Interacting point absorbers with controlled motion. In: Count B (ed) Power from sea waves. Academic Press, London, pp 381-399

63. Budal K, Falnes J, Iversen PM et al (1982) The Norwegian wave power buoy project. In: The second international symposium on wave energy utilization, pp 323-344

64. Korde U (2002) Latching control of deep water wave energy devices using an active reference. Ocean Eng 29:1343-1355. doi:10.1016/S0029-8018(01)00093-2

65. Babarit A, Duclos G, Clement AH (2004) Latching control of power take off oscillator carried by a wave activated body. In: International workshop on water waves and floating bodies (IWWWFB), Longyearbyen, Norway

66. Beirão P, Valério D, Sá Da Costa J (2006) Phase control by latching applied to the Archimedes wave swing. In: Controlo 2006 Lisboa 7th Portuguese conference on automatic control

67. Bjartelarsson T, Falnes J (2006) Laboratory experiment on heaving body with hydraulic power take-off and latching control. Ocean Eng 33:847-877. doi:10.1016/j.oceaneng.2005.07.007

68. Nolan GA, Ringwood JV, Leithead W, Butler S (2005) Optimal damping profiles for a heaving buoy wave-energy converter. In: The fifteenth international offshore and polar, engineering conference, vol 8, pp 477-484

69. Ringwood JV, Butler S (2004) Optimisation of a wave energy converter. In: Control applications in marine systems IFAC conference on CAMS 2004, pp 155-160

70. Salter SH, Taylor JRM, Caldwell NJ (2002) Power conversion mechanisms for wave energy. Proc Inst Mech Eng M 216:1-27. doi:10.1243/147509002320382103
71. Wright A, Beattie WC, Thompson A et al (2003) Performance considerations in a power take-off unit based on a non-linear load. In: Proceedings of 5 th European wave energy conference

72. Babarit A, Guglielmi M, Clément AH (2009) Declutching control of a wave energy converter. Ocean Eng 36:1015-1024. doi: 10.1016/j.oceaneng.2009.05.006

73. Falcao A (2008) Phase control through load control of oscillatingbody wave energy converters with hydraulic PTO system. Ocean Eng 35:358-366. doi:10.1016/j.oceaneng.2007.10.005

74. Clément AH, Babarit A (2012) Discrete control of resonant wave energy devices. Philos Trans A 370:288-314. doi:10.1098/rsta. 2011.0132

75. Salter SH (1980) Apparatus for extracting power from waves on water

76. Korde UA (2000) Control system applications in wave energy conversion. In: OCEANS 2000 MTS/IEEE conference and exhibition conference proceedings (Cat. No. 00CH37158), IEEE, Providence, Rhode Island, USA, pp 1817-1824

77. Falnes J (2002) Optimum control of oscillation of wave-energy converters. Int J Offshore Polar Eng 12:147-155

78. Falcão AFDO, Justino PAP, Henriques JCC, André JMCS (2009) Reactive versus latching phase control of a two-body heaving wave energy converter. In: European control conference, Budapest, Hungary, pp 3731-3736

79. Payne GS, Taylor JRM, Parkin P, Salter SH (2006) Numerical modelling of the sloped IPS buoy wave energy converter. In: 16th International offshore and polar engineering conference. International Society of Offshore and Polar Engineers, pp 396-402

80. Campo PJ, Morari M (1987) Robust model predictive control. In: 1987 American control conference, vol 2, pp 1021-1026. doi: 10.1049/iet-cta

81. Camacho E, Bordons C (2003) Model predictive control. Springer, New York

82. Richter M (2011) Different model predictive control approaches for controlling point absorber wave energy converters. University Stuttgart, Stuttgart

83. Gieske P (2007) Model predictive control of a wave energy converter: Archimedes wave swing. Delft University of Technology, Delft

84. Hals J, Falnes J, Moan T (2011) Constrained optimal control of a heaving buoy wave-energy converter. J Offshore Mech Arct Eng 133:011401. doi:10.1115/1.4001431

85. Bacelli G, Gilloteaux J-C, Ringwood J (2009) A predictive controller for a heaving buoy producing potable water. In: European control conference, pp 3755-3760

86. Bertsekas DP (1996) Dynamic programming and optimal control. Volume 1. J Oper Res Soc 47:833. doi:10.2307/3010291

87. Li G, Weiss G, Mueller M et al (2012) Wave energy converter control by wave prediction and dynamic programming. Renew Energy 48:392-403. doi:10.1016/j.renene.2012.05.003

88. Schoen MP, Hals J, Moan T (2008) Wave prediction and fuzzy logic control of wave energy converters in irregular waves. In: 2008 16th Mediterranean conference on control and automation, pp 767-772. doi:10.1109/MED.2008.4602036

89. See PC, Tai VC, Molinas M (2012) Ant colony optimization applied to control of ocean wave energy converters. Energy Procedia 20:148-155. doi:10.1016/j.egypro.2012.03.016

90. Cruz J (2008) Ocean wave energy. Ocean Wave. Energy 10:978973

91. Evans DV, Porter R (1997) Efficient calculation of hydrodynamic properties of OWC-type devices. J Offshore Mech Arct Eng 119:210. doi:10.1115/1.2829098

92. Tedd J, Kofoed JP, Jasinski M et al (2007) Advanced control techniques for WEC wave dragon. In: Proceedings of the 7th European wave and tidal energy conference: EWTEC (2007). European Ocean Energy Association, Porto, pp 211-214 
93. Miyazaki T, Yokomizo H, Hotta H, Washio Y (1988) A fundamental research of air flow phase control for improving on wave power absorption. J Kansai Soc Nav Archit 188

94. Hoskin RE, Count BM, Nichols NK, Nicol DAC (1986) Phase control for the oscillating water column. In: Hydrodynamics of ocean wave-energy utilization. Springer, Berlin

95. The Carbon Trust (2005) Oscillating water column WEC evaluation report
96. Nunes G, Valério D, Beirão P, Sá Da Costa J (2011) Modelling and control of a wave energy converter. Renew Energy 36:1913-1921. doi:10.1016/j.renene.2010.12.018

97. Falcão A (1999) OWC wave energy devices with air flow control. Ocean Eng 26:1275-1295. doi:10.1016/S0029-8018(98)00075-4

98. Chatry G, Clement AH, Sarmento AJNA (2000) Simulation of a self-adaptively controlled OWC in a nonlinear numerical wave tank. Int J Offshore Polar Eng 10:269-275 